\title{
Quality of work life: Effects on turnover intention and organisational commitment amongst selected South African manufacturing organisations
}

\begin{tabular}{|c|c|}
\hline \multicolumn{2}{|c|}{$\begin{array}{l}\text { Authors: } \\
\text { Vernise Els }{ }^{1} \\
\text { Marissa Brouwers } \\
\text { Roslyn B. Lodewyk } \\
\text { Ro }\end{array}$} \\
\hline \multicolumn{2}{|c|}{$\begin{array}{l}\text { Affiliations: } \\
{ }^{1} \text { Department of Human } \\
\text { Resource Sciences, Faculty of } \\
\text { Economic and Management } \\
\text { Sciences, North-West } \\
\text { University, Potchefstroom, } \\
\text { South Africa }\end{array}$} \\
\hline \multicolumn{2}{|c|}{$\begin{array}{l}\text { Corresponding author: } \\
\text { Marissa Brouwers, } \\
\text { marissa.brouwers@nwu.ac.za }\end{array}$} \\
\hline \multicolumn{2}{|c|}{$\begin{array}{l}\text { Dates: } \\
\text { Received: } 30 \text { May } 2020 \\
\text { Accepted: } 28 \text { Oct. } 2020 \\
\text { Published: } 19 \text { Jan. } 2021\end{array}$} \\
\hline \multicolumn{2}{|c|}{$\begin{array}{l}\text { How to cite this article: } \\
\text { Els, V., Brouwers, M., \& } \\
\text { Lodewyk, R.B. (2021). } \\
\text { Quality of work life: Effects } \\
\text { on turnover intention and } \\
\text { organisational commitment } \\
\text { amongst selected South } \\
\text { African manufacturing } \\
\text { organisations. SA Journal } \\
\text { of Human Resource } \\
\text { Management/SA Tydskrif vir } \\
\text { Menslikehulpbronbestuur, } \\
\text { 19(0), a1407. https://doi. } \\
\text { org/10.4102/sajhrm. } \\
\text { v19i0.1407 }\end{array}$} \\
\hline \multicolumn{2}{|c|}{$\begin{array}{l}\text { Copyright: } \\
\text { (C) 2021. The Authors } \\
\text { Licensee: AOSIS. This } \\
\text { is licensed under the } \\
\text { Creative Commons } \\
\text { Attribution License. }\end{array}$} \\
\hline \multicolumn{2}{|l|}{ Read online: } \\
\hline 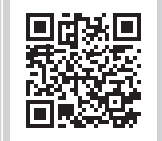 & $\begin{array}{l}\text { Scan this QR } \\
\text { code with your } \\
\text { smart phone or } \\
\text { mobile device } \\
\text { to read online. }\end{array}$ \\
\hline
\end{tabular}

Orientation: Quality of work life has a significant impact on an organisation. Therefore, it is imperative to gain knowledge about quality of work life and the relationship it has with organisational commitment and turnover intention.

Research purpose: The general objective of this study was to examine the relationship between quality of work life and turnover intention and to see whether organisational commitment mediates the relationship between quality of work life and turnover intention.

Motivation for the study: The lack of research on the relationships between quality of work life, turnover intention and organisational commitment make it challenging to gain knowledge on the concepts and what influences it can have to embrace these relationships in the workplace.

Research design: A cross-sectional study with a sample of $N=400$ South African manufacturing organisation employees was utilised. Descriptive statistics, Pearson's product-moment correlations and structural equation modelling were used.

Main findings: The results indicated both direct and indirect effects for all the relationships. Results further indicated that organisational commitment partially mediates the relationship between the quality of work life and turnover intention.

Practical implications: The results provided insight into the effect that high levels of quality of work life has on an individual and the advantages for the organisation.

Contribution: The improved understanding of quality of work life and the relationship with certain job outcomes contribute to the body of knowledge on both the theory of quality of work life and on employees' experience of turnover intention and commitment in the work environment.

Keywords: quality of work life; turnover intention; organisational commitment; manufacturing industry; South Africa.

\section{Introduction}

Employees can be considered as the most valued asset within a company (Gopinath, 2020). Gopinath (2020) states that employees make substantial contributions to an organisation's existing bottom line. Thus, such human capital should be managed with respect and dignity, whilst trusting and investing in them to reach the organisation's goals on time. The manufacturing industry contributes $14 \%$ to the gross domestic product (GDP) and is the fourth largest sector in South Africa (IDC, 2019). According to South African (2019) statistics, the manufacturing sector is currently $19.1 \%$ underutilised, which means that the industry is only utilising $80.9 \%$ of its full potential. Therefore, an employee can be regarded as a valuable asset within the manufacturing industry, contributing to the growth and effectiveness of the sector (Hooi \& Zahari, 2020). Gopinath (2020) mentions that when employees do not feel acknowledged in an organisation, such a company will find it difficult to face challenges regarding individual employees and the effectiveness of the organisation, therefore satisfied and motivated employees are important for businesses such as the manufacturing industry.

The manufacturing industry faces global market demands and challenges with employees within the organisation (Campbell, De Beer, \& Pei, 2011). These demands include the global market centres on electricity supply, volatile currency, productivity level, limited budget and technology, acquisitions, downsizing, mergers, retrenchments and competitors (Campbell et al., 2011; Marshall \& Stephenson, 2020; Potgieter \& Mokomane, 2020). Challenges for the 
manufacturing industry involving its employees are absenteeism, job insecurity, burnout, turnover intention, lack of commitment, low productivity, discomfort in the work environment and insufficient communication (Campbell et al., 2011; Marshall \& Stephenson, 2020; Paltu \& Brouwers, 2020; Potgieter \& Mokomane, 2020). It is the responsibility of the human resource department (HRD) to develop strategies that deal with the mentioned challenges that will enable them to better manage other demands experienced in the industry (Potgieter \& Mokomane, 2020).

To be a valuable resource to the organisation, employees need a positive outlook both on their work and life and strike a positive balance between their work and personal needs and goals. Thus, employees who demonstrate high levels of quality in their work life and organisational commitment are considered to experience a healthy balance between their work and personal needs (Gayathiri \& Ramakrishan, 2013). In this regard, an organisation's HRD is encouraged to develop strategies such as interventions, workshops and training for employees. This will benefit their employees, which will increase the quality of their work life and enhance their commitment to the organisation (Gayathiri \& Ramakrishan, 2013). As employees experience a higher quality of work life, the organisation's output and effectiveness will escalate accordingly (Gayathiri \& Ramakrishan, 2013). Therefore, if the HRD develops strategies to increase quality of work life and organisational commitment, the employees will feel a sense of belonging and experience that their value in the organisation is appreciated (Sahni, 2019).

As mentioned before, the organisation must at times deal with challenges from employees, such as absenteeism or increasing turnover intention in the workplace (Islam, 2012). The reason is that employees often perceive their work demands as high and that the organisation does not regard them as valuable (Hussain \& Asif, 2012). Turnover intention can be defined as individuals who are considering leaving the organisation and thus are seeking alternative work opportunities (Bothma \& Roodt, 2013). Previous research made it clear that quality of work life has an effect on the level of turnover intention in an organisation (e.g. Almalki, FritzGerald, \& Clark, 2012; Kruger et al., 2002; Mosadeghrad, 2013a; Mosadeghrad, Ferlie, \& Rosenberg, 2011).

Quality of work life can be described as the degree to which employees satisfy their personal and working needs, whilst performing tasks in that organisation (Swamy, Nanjundeswara, \& Rashmi, 2015). Earlier studies indicated that quality of work life has a negative relationship with turnover intention; in other words, when quality in an employee's work life increases, turnover intention in the organisation will likely be less (Lee, Dai, Park, \& McCreary, 2013). Employees then have a positive work environment, motivation to work, their personal and working needs are fulfilled and they experience a sense of pleasure whilst going to work (Lee et al., 2013). Therefore, it is necessary that organisations develop strategies to improve employees' quality of work life, allowing the company to be more effective and productive (Normala, 2010).

Studies were carried out earlier to assess the relationship between quality of work life and turnover intention (i.e. Almalki et al., 2012; Kruger et al., 2002; Mosadeghrad, 2013; Mosadeghrad et al., 2011; Lee et al., 2013). However, most of the studies were carried out internationally and not in the South African context. Therefore, there is a need to investigate the relationship further involving quality of work life and turnover intention within a South African setting.

Organisational commitment can be seen as the way employees form an attachment to the company where they work (Shanawaz \& Jafri, 2009). Organisational commitment has a positive effect on performance in the workplace (Sahni, 2019). Employees who experience healthy levels of attachment to the organisation, will feel a stronger commitment to the organisation, which will increase their performance (Albdour \& Altarawneh, 2014; Sahni, 2019). The levels of organisational commitment individuals experience within the workplace can have an impact on employees' thinking and behaviour (Mahmoudi, 2015). In other words, if employees enjoy high levels of quality in their work life and attachment to the organisation, they will develop a positive behaviour towards the organisation, which will have a positive effect on performance and company effectiveness (Mahmoudi, 2015; Sahni, 2019).

Ismail and Alipour (2014) found that quality of work life and organisational commitment has a close relationship. Thus, when employees experience decreased levels in the quality of their work life, they will also experience lower levels in their commitment to the organisation. Prior studies indicated that quality of work life has a positive relationship with affective and normative commitment, but a negative relationship with continuance commitment (i.e. Afsar, 2014; Chinomona, Dhurup, \& Chinomona, 2014; Ismail \& Alipour, 2014; Louis, 2006; Mahmoudi, 2015; Risla \& Ithrees, 2018).

Yusoff, Rimi and Meng (2015) examined the relationship between quality of work life and turnover intention with a mediator of organisational commitment. A mediator can be described as a means to examine the relationship between an independent variable and dependent variable and the relationship of both with the mediator, respectively (Bennett, 2000). Yusoff et al. (2015) found that quality of work life and turnover intention is mediated partially by affective and normative commitment; however, that continuance commitment has no mediation effect on quality of work life and turnover intention. Currently, there is limited research on the mediating effect of organisational commitment and on the relationship between quality of work life and turnover intention within the South African context, therefore, it is necessary to examine the mediating effect. 


\section{Research purpose and objectives}

The general objective of this study was to examine the relationship between quality of work life and turnover intention. Furthermore, this study also investigated whether organisational commitment mediates the relationship between quality of work life and turnover intention.

More specifically the objective of this study was:

- to establish the relationship between quality of work life and turnover intention amongst employees within selected South African manufacturing organisations

- to determine whether organisational commitment (e.g. affective, normative and continuance commitment) mediate the relationship between quality of work life and turnover intention amongst employees within selected South African manufacturing organisations.

\section{Literature review Quality of work life}

Swamy et al. (2015) conceptualised quality of work life as the degree to which employees are satisfied with their personal and working needs, by the experience to which they are exposed in the organisation. Swamy et al. (2015) investigated quality of work life constructed on nine components, which are: (1) Work environment: It entails the professional and social environment that workers experience whilst interacting with one another (Sinha, 2012), (2) Organisational culture and climate: Organisational culture can be seen as a set of aspects that contribute to the norm and vision of a workplace (Wallace, Hunt, \& Richards, 1999). Organisational climate relates to the way employees behave, which forms part of the organisation's values and norms (Wallace et al., 1999), (3) Relations and co-operations: Relations and co-operations are the degree to which employers and workers interact in communication, decision-making, problem-solving and conflict handling (Bray, Budd, \& Macneil, 2019), (4) Training and development: Training and development are a set of ways in which workers can be involved in enhancing their knowledge and skills within the workplace (Noe, 2010), (5) Compensation and rewards: compensation and rewards are a technique utilised to motivate employees in the workplace (Swamy et al., 2015), (6) Facilities: It can be perceived as resources and infrastructure such as the food service, transportation, security, which contribute to the satisfaction of the physical and emotional needs of employees (Jensen, 2011), (7) Job satisfaction and job security: Job satisfaction is seen as the outlook employees have in their occupation, work environment and workplace, whether it be positive or negative (Aziri, 2011). Employees who experience job insecurity indicate an apprehension about the continued existence of their job and whether the organisation will keep them as worker (Moshoeu \& Geldenhuys, 2015), (8) Autonomy of work: It is a way by which organisations afford their employees more freedom by giving them the space to make decisions, control work-related activities and co-ordinate job structures (Swamy et al., 2015) and (9) Adequacy of resources:
It is based on time, equipment, information and supervisory help to complete job tasks in the company (Mahesh \& Nanjundeswaraswamy, 2020; Nanjundeswaraswamy, Swamy, \& Nagesh, 2019; Nenadal, 2016).

\section{The relationship between quality of work life, turnover intention and organisational commitment}

\section{Turnover intention}

Bothma and Roodt (2013) articulated turnover intention as employees experiencing negative emotions towards the organisation and, therefore, are weighing their options, whether or not to leave the organisation. The relationship between quality of work life and turnover intention is seen as a significantly negative relationship (Huang, Lawler, \& Lei, 2007). This might indicate that when workers experience increased levels of quality in their work life, the organisation will face decreased levels of turnover intention, contributing to its effectiveness (Korunka, Hoonakker, \& Carayon, 2008). Huang et al. (2007) examined the relationship of quality of work life on organisational commitment and turnover intention in Taiwan and indicated a significant negative relationship. Previous studies confirmed that quality of work life has a significantly negative relationship with turnover intention in the manufacturing and accounting industries of Malaysia (Ramayah, Lo, \& Tarmizi, 2014; Yusoff et al., 2015).

Furthermore, quality of work life and turnover intention showed a significantly negative relationship within the service, technology and hospital sector in Iran, India and Indonesia (Korunka et al., 2008; Kumar \& Thomas, 2016; Mosadeghrad, 2013; Rostiana, 2017). A further study examining the hospital service, particularly primary healthcare nurses, established a negative relationship between quality of work life and turnover intention in the Saudi Arabian region (Almalki et al., 2012). The relationship between these variables was tested in Zimbabwe, in the Southern African continent; previous studies also indicated similar outcomes within small and medium enterprises (Chinomona et al., 2014). A study performed amongst staff nurses showed that there is a negative relationship between quality of work life and intention to leave (Elshahat, Shazly, \& Abd-Elazeem, 2019). Furthermore, Indhumathi, Balaji and Hemalatha (2019) found a negative relationship between quality of work life and turnover intention. Although previous research on this topic covered several industries, there is no evidence that the relationship between quality of work life and turnover intention was investigated in the South African context to date, thus the current study investigated this relationship.

\section{Organisational commitment}

Organisational commitment can be described as the psychological attachment employees establish with their workplace (Metin \& Asli, 2018). Similarly, Shanawaz and 
Jafri (2009) conceptualised organisational commitment as the level of attachment employees experience towards their organisation. Allen and Meyer (1990) considered a three-construct model, where organisational commitment influences the connection that employees have with their workplace. These constructs consist of: (1) Affective commitment which occurs when workers identify with the organisation on an emotional level, thus they experience a sense of loyalty and desire to remain at the organisation (Allen \& Meyer, 1996), (2) Normative commitment which refers to when employees feel the obligation to stay on at the organisation, even though they experience dissatisfaction (Allen \& Meyer, 1996) and (3) Continuance commitment which is observed when employees stay on at the organisation because they invested skills, knowledge, abilities and time in the company and risking these efforts are deemed too high (Allen \& Meyer, 1996).

Yusoff et al. (2015) and Rostiana (2017) applied organisational commitment as mediator in the relationship between quality of work life and turnover intention within the manufacturing industry and service sector in Malaysia and Indonesia. They found that organisational commitment partially mediates the relationship between quality of work life and turnover intention. The research on relationships between organisational commitment and turnover intention can be valuable to help establish the link between the intention to leave work whilst forming a psychological bond with the organisation (Chang, Chi, \& Miao, 2006). A study carried out by Sahni (2019) in the telecom industry found that quality of work life is positively related to organisational commitment. Furthermore, Nanjundeswaraswamy et al. (2019) did a study in small and medium sized enterprises and also found a positive relationship between quality of work life and employee commitment.

Regarding the South African context, a literature review and studies focused on the relationship between quality of work life and other variables such as perceived service delivery, productivity and organisational trust (Kotze, 2004, 2005; Van der Berg \& Martins, 2013; Viljoen, Kruger, \& Saayman, 2014). However, there is no evidence that the relationship between quality of work life and organisational commitment was investigated, which the present study, thus examines.

\section{Research design \\ Research approach}

A quantitative research approach was utilised. Such an approach is described as statistical procedures and numbers that can be used to determine the sample fitting, which the study describes as true (Creswell, 2014). The present research was descriptive and a cross-sectional research design was used. Such a research design suited the study the best because it provides the opportunity to measure a group of people at a single point in time, thus making the study more cost-efficient (Creswell, 2014).

\section{Research participants}

The target population involved selected South African manufacturing organisations, with a population size of $N=400$. A combined method of convenience and purposive non-probability sampling was utilised. The respondents differed in terms of age and highest qualification, which made them suitable for participating in this study. The questionnaire was compiled in English, therefore candidates able to read, write and understand this language were selected to partake in this study. The respondents' ages ranged from 18 to 65 years. The respondents were mostly from the age group of 30-39 years (35\%). In addition, 29.3\% of respondents obtained a high school qualification or diploma, followed by $19.8 \%$ who gained a degree and $16.5 \%$ gained a postgraduate degree. In addition, $5.4 \%$ of the respondents identified other highest qualifications such as ABET (0.8\%), Boilermaker (0.3\%), Certificates (2.5\%), Grade $11(1.5 \%)$ and an South African National Qualification Framework (NQF) level $3(0.3 \%)$.

\section{Measuring instruments}

The measuring instruments used in the study are expounded here.

Biographical questionnaire: This questionnaire, included in the study, provided information on the participants' demographical characteristics. This provided the opportunity to investigate the participants' age, job level and highest qualification. The questionnaire was used only to describe the data.

The quality of work life scale: It was developed by Swamy et al. (2015). The quality of work life scale utilises 50 items of which 47 items were used and are divided into nine dimensions. The nine dimensions are as follows: Work environment (e.g. 'My company work environment is good and highly motivating'); Organisation culture and climate (e.g. 'There is cooperation amongst all the departments for achieving the goals'); Relation and co-operation (e.g. 'There is a harmonious relationship with my colleagues'); Training and development (e.g. 'The training programs aim at improving interpersonal relationships amongst employees'); Compensation and rewards (e.g. 'I feel that I am given an adequate and fair compensation for the work I do'); Facilities (e.g. 'Fringe benefits provided are good'); Job satisfaction and job security (e.g. 'I feel comfortable and satisfied with my job'); Autonomy of work (e.g. 'My job lets me use my skills and abilities') and Adequacy of resources (e.g. 'There are much defined channels for information exchange and transfer'). A five-point Likert scale was used (1, strongly disagree; 2, disagree; 3, uncertain; 4, agree and 5, strongly agree). Swamy et al. (2015) found the reliability coefficient of the questionnaire to be 0.80 , which means that it can be considered as strongly reliable. The reliability coefficients in this study for Quality of Work Life ranged between 0.76 and 0.92 . 
Turnover intention scale was developed by Bothma and Roodt (2013). This scale utilises six items, with an example: 'To what extent is your current job satisfying your personal needs?'. The questionnaire consists of a five-point Likert scale (1, never to 5, always). Bothma and Roodt (2013) found the reliability at 0.80 . The reliability coefficients in this study for the turnover intention scale was 0.90 .

The Organisational Commitment scale was developed by Allen and Meyer (1990). The instrument utilises 24 items, which are divided into three dimensions. The dimensions are: affective commitment (e.g. 'I enjoy discussing my organisation with people outside it'), continuance commitment (e.g. 'It would not be too costly for me to leave my organisation now') and normative commitment (e.g. 'I think that people these days move from company to company too often'). The questionnaire makes use of a seven-point Likert scale (1, strongly disagree to 7, strongly agree). Allen and Meyer (1990) found the reliability coefficient for the three components are: affective commitment: 0.87 ; continuance commitment: 0.75 and normative commitment: 0.79 . The reliability coefficients for the organisation commitment scale in this study were 0.92 for affective commitment; 0.75 for continuous commitment and 0.78 for normative commitment.

\section{Research procedure and ethical considerations}

The researchers took the responsibility to ensure respondents and the company that no employee would be obliged and that involvement in the study is voluntary (Simons \& Usher, 2000). The researchers made sure that no participants suffered emotional or physical harm (Bell, Bryman, \& Harley, 2019). This was accomplished by not withholding any information regarding the study from the respondents (Bell et al., 2019). In addition, the researcher ensured that all questionnaires were anonymous by only including a number to the booklet, instead of participants' names. Furthermore, the questionnaires are kept in a safe place with limited access (Simons \& Usher, 2000). Thus, only the researchers have access to the data.

Once permission was granted by the manufacturing organisations, the procedure of the study was explained to all employees of the respective companies via electronic mail; prior to this, the human resource manager of the respective organisations sent a notice to all employees, informing them of the research being conducted. Their only role was to inform the company of the study and grant permission for the research. Thereafter, the questionnaires were distributed by the researchers to all participants together with an informed consent form. The questionnaire consisted of a pen and paper booklet. Once the consent form was signed, the researcher explained that the respondents had 3 weeks to complete the questionnaire. After 3 weeks, the researcher collected the questionnaires. A total of 400 questionnaires were distributed, and all 400 were returned for data analyses. During data analyses, the data were cleaned (i.e. missing responses were removed) and statistical analyses were conducted.

\section{Statistical analyses}

The statistical analyses were carried out using the Statistical Package for Social Science (SPSS) version 25 (IBM Corp, 2017) and AMOS programme (Arbuckle, 2007). The data were examined through descriptive statistics that explored the data in terms of mean, standard deviations, skewness and kurtosis. Cronbach's alpha coefficients were calculated to measure the reliability of the scale's dimensions. Should the coefficient be $>0.70$, the variables measured were considered reliable (Tabachnick \& Fidell, 2001).

Product-moment correlation was used to examine the relationship between variables of the study. The cut-off points for practical significance of the correlations was set at $r<0.30$ (small effect), $0.30<r<0.50$ (medium effect) and $r>0.50$ (large effect). The cut-off points for statistical significance was set at $p<0.1$ level $(*)$ or $p<0.5$ level (**) (Hauke \& Kossowski, 2011).

Structure equation modelling (SEM) using AMOS (Arbuckle, 2007) was employed to measure the proposed mediation model of organisational commitment between quality of work life and turnover intention. Several goodness-of-fit indices were used, namely Chi-square $\left(\chi^{2}\right)$, the comparative fit index (CFI) Tucker-Lewis index (TLI) and the root mean square error of approximation (RMSEA). Acceptable cut-off points for goodness-of-fit indices are as follows: nonsignificant $\chi^{2}$ values; CFI and TLI values larger than or equal to 0.90 and RMSEA values smaller than or equal to 0.08 (Byrne, 2010).

\section{Results \\ Descriptive statistics}

It is evident from the results in Table 1 that all the scales were distributed normally, according to the guidelines of skewness $(<2)$ and kurtosis $(<4)$ (Nethmini \& Ismail, 2019). Furthermore, training and development as a quality of

TABLE 1: Descriptive statistics of the constructs.

\begin{tabular}{lcccc}
\hline Constructs & Mean & SD & Skewness & Kurtosis \\
\hline Work environment & 3.37 & 0.91 & -0.53 & -0.54 \\
Organisation culture and climate & 3.46 & 0.96 & -0.47 & -0.63 \\
Relation and co-operation & 3.51 & 0.89 & -0.43 & -0.60 \\
Training and development & 3.61 & 0.92 & -0.47 & -0.54 \\
Compensation and rewards & 3.23 & 1.11 & -0.43 & -0.76 \\
Facilities & 3.30 & 0.97 & -0.42 & -0.57 \\
Job satisfaction and job security & 3.38 & 1.10 & -0.59 & -0.63 \\
Autonomy of work & 2.99 & 0.96 & -0.15 & -0.71 \\
Adequacy of resources & 3.26 & 1.11 & -0.34 & -0.86 \\
Affective commitment & 3.95 & 0.62 & 0.17 & 1.11 \\
Continuance commitment & 4.48 & 1.02 & -0.26 & -0.20 \\
Normative commitment & 4.24 & 0.67 & -0.09 & 1.22 \\
Turnover intention & 2.91 & 1.07 & 0.16 & -1.02 \\
\hline
\end{tabular}

SD, standard deviation. 
work life scale' mean was experienced more compared with the rest. Respondents also experienced higher continuous commitment and average turnover intention.

\section{Correlations}

The correlation coefficients between the constructs are presented in Table 2.

The first objective of the present study was to determine the relationship between quality of work life and turnover intention. The quality of work life components investigated are: Work environment: It indicates a statistically negative relationship with turnover intention with a large effect ( $r=-0.72)$; Organisation culture and climate: It indicates statistically negative relationship with turnover intention with a large effect $(r=-0.73)$; Relations and co-operation: It indicates statistically negative relationship with turnover intention with a large effect $(r=-0.74)$; Training and development: It shows statistically negative relationship with turnover intention with a large effect $(r=-0.60)$; Compensation and reward: It shows statistically negative relationship with turnover intention with a large effect $(r=-0.75)$; Facilities: It shows statistically negative relationship with turnover intention with a large effect $(r=-0.61)$; Job satisfaction and job security: It shows statistically negative relationship with turnover intention with a large effect $(r=-0.79)$; Autonomy of work: It shows statistically negative relationship with turnover intention with a large effect $(r=-0.69)$ and Adequacy of resources: It indicates statistically negative relationship with turnover intention with a large effect $(r=-0.72)$. From the findings, all nine components from quality of work life indicated a statistically significant negative relationship (with a large effect) with turnover intention (ranging between $r=-0.60$ and $r=-0.79$ ). In other words, when quality of work life improves the turnover intention will decrease.

\section{Mediation analysis}

The second objective of the present study was to investigate whether organisational commitment mediates the relationship between quality of work life and turnover intention. Structural equation modelling was employed to test the proposed mediating effect. The given hypothesised mediation model (as indicated in Figure 1) tested whether organisational commitment as a latent variable mediates the relationship between quality of work life as a latent variable and turnover intention.

Structural equation modelling was employed to test the proposed mediating effect of organisational commitment between quality of work life and turnover intention (as depicted in Figure 1). The proposed mediating effect of organisational commitment between quality of work life and turnover intention was tested, and it is evident from Table 3 that the structural mediation model has a good fit. The CFI (0.95) and the TLI (0.94) were both found above the rule of thumb of 0.90, which indicates good model fit (Byrne, 2010). The RMSEA value (0.08) was also aligned with the guideline of 0.08, which confirmed a good model fit (Byrne, 2010). As is clear from Figure 1, the results indicate a significant positive relationship between quality of work life and organisational commitment $\left(R^{2}=0.91\right.$; standard error $[\mathrm{SE}]=0.06 ; p=0.00)$. Furthermore, the findings showed a significant negative relationship between organisational commitment and turnover intention $\left(R^{2}=-0.53\right.$; $\mathrm{SE}=0.11$, $p=0.00)$. The results, therefore, indicated a significant negative relationship between quality of work life and turnover intention $\left(R^{2}=0.40 ; \mathrm{SE}=0.06, p=0.00\right)$. The mediation was found to be partial for the model

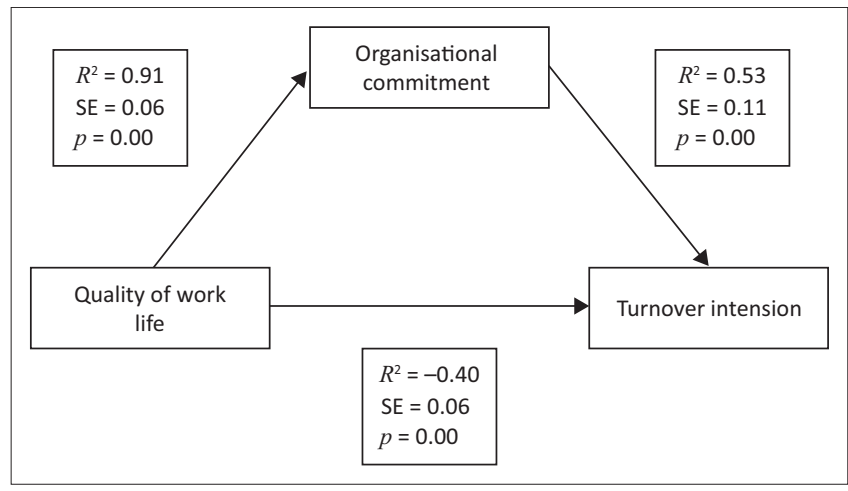

FIGURE 1: Organisational commitment mediation over all models. SE, standard error.

TABLE 3: Goodness-of-fit statistics for structural model.

\begin{tabular}{lcccccc}
\hline Models & $\chi^{2}$ & $\chi^{2} / \mathrm{df}$ & TLI & CFI & RMSEA & $\boldsymbol{p}$ \\
\hline Model (turnover intention) & 463293 & 3.510 & 0.94 & 0.95 & 0.08 & 0.00
\end{tabular}

TLI, Tucker-Lewis index; CFI, comparative fit index; RMSEA, root mean square error of approximation.

TABLE 2: Correlation matrix between variables.

\begin{tabular}{|c|c|c|c|c|c|c|c|c|c|c|}
\hline Variables & 1 & 2 & 3 & 4 & 5 & 6 & 7 & 8 & 9 & 10 \\
\hline 1. Work environment & 1.00 & - & - & - & - & - & - & - & - & - \\
\hline 2. Organisational culture and climate & $0.83 * \dagger$ & 1.00 & - & - & - & - & - & - & - & - \\
\hline 3. Relation and co-operation & $0.78 * \dagger$ & $0.80 * \dagger$ & 1.00 & - & - & - & - & - & - & - \\
\hline 4. Training and development & $0.65 * \dagger$ & $0.67 * \dagger$ & $0.65 * \dagger$ & 1.00 & - & - & - & - & - & - \\
\hline 5. Compensation and reward & $0.79 * \dagger$ & $0.80 * \dagger$ & $0.77 * \dagger$ & $0.65 * \dagger$ & 1.00 & - & - & - & - & - \\
\hline 6. Facilities & $0.64 * \dagger$ & $0.70 * \dagger$ & $0.62 * \dagger$ & $0.63 * \dagger$ & $0.72 * \dagger$ & 1.00 & - & - & - & - \\
\hline 8. Autonomy of work & $0.71 * \dagger$ & $0.70^{*} \dagger$ & $0.68 * \dagger$ & $0.60 * \dagger$ & $0.70 * \dagger$ & $0.57 * \dagger$ & $0.78 * \dagger$ & 1.00 & - & - \\
\hline 9. Adequacy of resources & $0.71 * \dagger$ & $0.78^{*} \dagger$ & $0.74 * \dagger$ & $0.59 * \dagger$ & $0.77 * \dagger$ & $0.66 * \dagger$ & $0.79 * \dagger$ & $0.76 * \dagger$ & 1.00 & - \\
\hline 10. Turnover intention & $-0.72 * \dagger$ & $-0.73 * \dagger$ & $-0.74 * \dagger$ & $-0.60 * \dagger$ & $-0.75 * \dagger$ & $-0.61 * \dagger$ & $-0.79 * \dagger$ & $-0.69 * \dagger$ & $-0.72 * \dagger$ & 1.00 \\
\hline
\end{tabular}

$*, p<0.01$ for all values.

$\dagger$, Correlation $>0.50$ is practically significant (large effect). 
that was tested and explained $63.1 \%$ of the variance in turnover intention.

\section{Discussion}

The general objective of this research study was to examine the relationship between quality of work life and turnover intention, as well as to determine whether organisational commitment mediates the relationship between quality of work life and turnover intention amongst employees within selected South African manufacturing organisations.

In South Africa, there is limited research to date on the relationship between quality of work life, turnover intention and organisational commitment (Chinomona et al., 2014; Van der Berg \& Martins, 2013; Viljoen et al., 2014). Therefore, the investigation on the relationships between quality of work life, turnover intention and organisational commitment demonstrated by employees from selected South African manufacturing organisations, will add to current literature in the field of human resource management. The objectives and accompanying results are outlined here.

The first objective was to determine the relationship between quality of work life and turnover intention amongst employees within selected South African manufacturing organisations. The results showed that all nine components (i.e. work environment, organisation culture and climate, relation and co-operation, training and development, compensation and rewards, facilities, job satisfaction and job security, autonomy of work and adequacy of resources) of quality of work life have a statistically significant negative relationship (with a large effect) with turnover intention. It is suggested that employees who experience higher levels of quality of work life will less likely leave the organisation (Kumar \& Thomas, 2016). Such a result can imply that employees wanting to stay at the organisation because of experiencing high quality in their work and life.

Furthermore, the findings indicated that employees with high levels of quality of work life will be able to satisfy their personal and working need whilst working in the organisation. Such a situation implies that those employees are satisfied and have no intention to leave the organisation (Yusoff et al., 2015). Previous studies found similar results indicating that quality of work life has a negative relationship with turnover intention (Almalki et al., 2012; Chinomona et al., 2014; Haung et al., 2007; Korunka et al., 2008; Kumar \& Thomas, 2016; Mosadeghrad, 2013a; Mosadeghrad et al., 2011; Ramayah et al., 2014; Yusoff et al., 2015).

The second objective for the present study was to establish whether organisational commitment (affective, continuance and normative commitment) mediates the relationship between quality of work life and turnover intention amongst employees within selected South African manufacturing organisations. The results indicated that the mediation model of organisational commitment is a good fit and provides a mediating effect between quality of work life and turnover intention. Furthermore, the results showed that organisational commitment has a significant positive relationship with quality of work life, but a significant negative relationship with the component turnover intention. In addition, this indicates that organisational commitment partially mediates (with a medium effect) the relationship between quality of work life and turnover intention. This may suggest that when employees experience both high levels of quality of work life and organisational commitment, the turnover intention in an organisation will decrease. Therefore, it is important that organisations implement strategies to improve the quality in their employees' work life, thus strengthening their commitment to the organisation, thereby improving the effectiveness and sustainability of the company (Nanjundeswaraswamy et al., 2019; Sahni, 2019; Yusoff et al., 2015). Organisational commitment is, therefore, needed in the relationship between quality of work life and turnover intention to enhance the experience of employees at the organisation and influence the need to remain at the organisation (Nanjundeswaraswamy et al., 2019; Sahni, 2019; Yusoff et al., 2015).

Yusoff et al. (2015) conducted a study on organisational commitment as mediator between the relationship of quality of work life and turnover intention and found similar results that organisational commitment partially mediates the relationship between the two variables. Rostiana (2017) studied organisational commitment as mediator between the two variables and found that organisational commitment fully mediates the relationship between quality of work life and turnover intention. A study carried out by Sahni (2019) in the telecom industry found that quality of work life is positively related to organisational commitment. Furthermore, Nanjundeswaraswamy et al. (2019) did a study in smalland medium-sized enterprises and also found a positive relationship between quality of work life and employee commitment. Therefore, it is confirmed that enhancement in employees' organisational commitment will increase the level in quality of their work life and significantly reduce their intention to leave the organisation (Nanjundeswaraswamy et al., 2019; Sahni, 2019; Yusoff et al., 2015).

\section{Practical implications}

The results of this study contributed to the body of knowledge on quality of work life and the relationship between certain variables. This was performed by examining the relationship between quality of work life, turnover intention and organisational commitment. The findings on the relationship between quality of work life and turnover intention will help manufacturing organisations understand the importance of increasing each employee's quality of work life and the outcomes it may have for the company. Employees will also be aware that because the organisation invested in their skills, knowledge, abilities and time they will more likely have the feeling of not wanting to leave the organisation. Furthermore, the findings make a contribution towards employees and management to understand the 
impact that organisational commitment can exert on their quality of work life. Thus, organisations may include this resource in their strategy to improve the quality of work life of their employees and their commitment and turnover intention.

Management will be able to develop and implement strategies or interventions for employees to enhance their quality of work life and strengthen their organisational commitment. As a result, employees will feel more motivated, satisfied and content in the organisation, lowering their chances to exit the organisation. The benefits of being aware of the relationship between these variables will have a positive impact on individual employees and organisations within the South African manufacturing industry.

\section{Limitations and recommendations}

Firstly, the study used a cross-sectional research design, which means that the data were collected at a single point in time (Creswell, 2014; Kaplan, 2004). The research also used the method of convenience and purposive sampling, thus participants were selected who were easily reachable and had the qualities to participate (Creswell, 2014; Kaplan, 2004). As a result, the research could not determine the relationship between variables over an extended period and the participants were not evenly spread to represent the content of the South African manufacturing organisations. Future research can consider diverse research designs, such as a longitudinal approach, to investigate the relationship between variables over an extended period. Moreover, a study can examine the relationships between variables, investigating certain time gaps between each data collection, to improve the quality of information and obtain better findings (Creswell, 2014; Kaplan, 2004). It is further recommended that researchers collect data evenly across South African manufacturing organisations for more accurate findings and robust data.

Secondly, the research used a questionnaire that respondents had to answer in their own time. This type of questionnaire improves the quality of information the researcher requires for the study, although, it can cause confusion on the meaning of the questions amongst participants. Therefore, the results may not be overly accurate for the relationships between certain variables (Bacon-Shone, 2015). Future researchers can employ different data-collection techniques for their studies, for example interviews or focus groups. Such techniques might help participants understand the meaning of questions more accurately, thereby improving the quality of the results.

Finally, it is suggested that future research involve employees from all the different company levels in the manufacturing industry. Such broader participation may improve the understanding of the relationships between variables and its mutual impact within the workplace.

\section{Conclusion}

The present study provided findings that showed that quality of work life had an impact on turnover intention. The study furthermore confirmed the mediating effect of organisational commitment in the relationship between quality of work life and turnover intention. The research study, thus contributes and add to the existing literature.

\section{Acknowledgements}

This article is based on the first author's dissertation of the degree of Magister Commercii in Human Resource Management at the North-West University, South Africa.

The authors would like to acknowledge Prof. Suria Ellis for the statistical analysis and Ds Claude Vosloo about the language editing of the dissertation. Furthermore, they also express their gratitude to Dr Marissa Brouwers as supervisor of the dissertation and Ms Roslyn Lodewyk as co-supervisor.

\section{Competing interests}

The authors declare that they have no financial or personal relationships that may have inappropriately influenced them in writing this article.

\section{Authors' contributions}

V.E. fulfilled the role of the primary researcher, and this study formed part of her masters' research dissertation. She was responsible for the conceptualisation of the article, collection of data, interpretation of the research results and the writing of the article. M.B. acted as supervisor and played an advisory role in this study and assisted in the conceptualisation of the study, design, describing statistical procedures and reporting and assisted in the writing of the research article. R.B.L. acted as co-supervisor and assisted in the writing of the research article.

\section{Funding information}

This study was supported by the North-West University (publishing of the article).

\section{Ethical consideration}

After the scientific clearance and ethical approval was obtained from the respective university committees, possible manufacturing organisations were approached through their Human Resource Departments to participate in the study. The research was proposed via email, with a thorough outline of the aim of the research. After the consideration of the human resources departments, a presentation was held in front of the managers of the manufacturing organisations to explain the aim and procedure of the study and to safeguard all ethical guidelines. Ethical clearance number: NWU-00604-17-S4. 


\section{Data availability statement}

Data sharing is not applicable to this article as no new data were analysed or created in this study.

\section{Disclaimer}

The views and opinions expressed in this article are those of the authors and do not necessarily reflect the official policy or position of any affiliated agency of the authors.

\section{References}

Afsar, S.T. (2014). Impact of quality of work life on organisational commitment: A comparative study on academicians working for state and foundation universities in Turkey. International Journal of Social Science, 3(4), 124-152.

Albdour, A.A., \& Altarawneh, I.I. (2014). Employee engagement and organizational commitment: Evidence from Jordan. International journal of business, 19(2), 192-212.

Allen, N.J., \& Meyer, J.P. (1990). The measurement and antecedents of affirmative continues and normative commitment to the organisation. Journal of Occupationa Phycology, 63(1), 1-18. https://doi.org/10.1111/j.2044-8325.1990.tb00506.x

Allen, N.J., \& Meyer, J.P. (1996). Affective continuance and normative to the organisation: An examination of the construct validity. Journal of Vocational Behaviour, 49(3), 252-276. https://doi.org/10.1006/jvbe.1996.0043

Almalki, M.J., FitzGerald, G., \& Clark, M. (2012). The relationship between quality of work life and turnover intention of primary health care nurses in Saudi Arabia. BMC Health Services Research, 12-314. https://doi.org/10.1186/1472-6963-12-314

Arbuckle, J.L. (2007). Amos 18 user's guide. Crawfordsville, IN: Amos Development Corporation.

Aziri, B. (2011). Job satisfaction: A literature study. Management, Research \& Practice, 3(4), 77-86.

Bacon-Shone, J. (2015). Introduction to quantitative research method. Hong Kong Graduate School, The University of Hong Kong.

Bell, E., Bryman, A., \& Harley, B. (2019). Business research methods (5th edn.). Oxford: Oxford University Press.

Bennett, J.A. (2000). Mediator and moderator variables in nursing research: Conceptual and statistical differences. Research in Nursing \& Health, 23(5), 415-420. https:// and statistical differences. Research in Nursing \& Health, 23(5), 415-420. https:
doi.org/10.1002/1098-240X(200010)23:5\%3C415::AID-NUR8\%3E3.0.CO;2-H

Bothma, C.F.C., \& Roodt, G. (2013). The validation of the turnover intention scale South African Journal of Human Resource Management, 11(1), 1-12. https://doi. org/10.4102/sajhrm.v11i1.507

Bray, M., Budd, J.W., \& Macneil, J. (2019). The many meanings of co-operations in the employment relationships and their implications. British Journal of Industria Relations, 10(11), 1-14. https://doi.org/10.1111/bjir.12473

Byrne, B.M. (2010). Structural equation modelling with Mplus: Basic concepts, applications and programming. New York, NY: Routledge.

Campbell, R.I., De Beer, D.J., \& Pei, E. (2011). Additive manufacturing in South Africa: Building on the foundation. Rapid Prototyping Journal, 17(2), 156-162. https:// doi.org/10.1108/13552541111113907

Chang, H.T., Chi, N.W., \& Miao, M.C. (2006). Testing the relationship between three-component organisational/occupational commitment and organisational/ occupational turnover intention using a non-recursive model. Journal of occupational turnover intention using a non-recursive model. Journal of
Vocational Behaviour, 70(2), 352-368. https://doi.org/10.1016/j.jvb.2006.10.001

Chinomona, R., Dhurup, M., \& Chinomona, E. (2014). The influence of the quality of working life on employee job satisfaction, organisational commitment and tenure intention in the SME sector in Zimbabwe. South Africa Journal of Economics \& Management Science, 17(4), 363-378. https://doi.org/10.4102/sajems.v17i4.296

Creswell, J.W. (2014). Research design: Qualitative, quantitative, and mixed methods approach (4th edn.). Thousand Oaks, CA: Sage.

Elshahat, E.M., Shazly, M.M., \& Abd-Elazeem, H. (2019). Relationship between quality of work life and turnover intention among staff nurses. Egyptian Journal of Healthcare, 10(1), 178-193. https://doi.org/10.21608/ejhc.2019.28793

Gayathiri, R., Ramakrishnan, L. (2013). Quality of work life: Linkage with job satisfaction and performance. International Journal of Business and Management Invention, 2(1), 1-8.

Gopinath, R. (2020). Role of employees' attitude in workplace. Gedrag \& Organisatie Review, 33(2), 1461-1475. https://doi.org/10.37896/GOR33.02/156

Hauke, J., \& Kossowski, T. (2011). Comparison of value of pearson's and spearman's correlation coefficient on the same sets of data. Questions Geographical, 30(2), 87-93. https://doi.org/10.2478/v10117-011-0021-1

Hooi, Y.P., \& Zahari, I. (2020). Turnover intention in manufacturing industry: SEM-PL analysis. Journal of Global Business and Social Entrepreneurship, 6(18), 27-40.

Huang, T.C., Lawler, J., \& Lei, C.Y. (2007). The effects of quality of work life on commitment and turnover intention. Social Behaviour \& Personality: An International Journal, 35(6), 735-750. https://doi.org/10.2224/sbp.2007.35.6.735

Hussain, T., \& Asif, S. (2012). Is employee's turnover intention driven by organisational commitment and perceived organisational support? Journal of Quality \& Technology Management, 8(2), 1-10.
Indhumathi, R., Balaji, R., \& Hemalatha, S. (2019). A study on the quality of work life and turnover intention of employees in a textile mill. International Journal of Agricultural Science and Research, 9(4). 7-14. https://doi.org/10.24247/ ijasraug20192

Industrial Development Corporation of South Africa (IDC). (2019). 2019 integrated report. Retrieved from http://www.idc.co.za/ir2019/pdfs/intergrated.pdf

Islam, M.B. (2012). Factors affecting quality of work life: An analysis on employees private limited companies in Bangladesh. Global Journal of Management \& Business Research, 12(18), 27-56.

Ismail, I.A., \& Alipour, F. (2014). Relationship between quality of work life and organisational commitment among lectures in Malaysian public research University. Social Science Journal, 52(1), 231. https://doi.org/10.1016/j.soscij. 2014.09.003

Jensen, P.A. (2011). Organisation of facilities management in relation to core business. Journal of Facilities Management, 9(2), 78-95. https://doi.org/10.1108/ 14725961111128443

Kaplan, D. (2004). The SAGE handbook of quantitative methodology for the socia sciences. Thousand Oaks, CA: Sage.

Korunka, C., Hoonakker, P.L.T., \& Carayon, P. (2008). Quality of working life and turnover intention in information technology work. Human Factors \& Ergonomics in Management, 18(4), 409-423. https://doi.org/10.1002/hfm.20099

Kotze, T. (2004). Quality of work life: What managers need to know. Management Today, 20(6), 38-41.

Kotze, T. (2005). The nature and development of the construct 'quality of work life'. Acta Academic, 37(2), 96-122.

Kruger, P., Brazil, K., Lohfeld, L., Edward, H.G., Lewis, D., \& Tjam, E. (2002). Organisation specific predictors of job satisfaction: Findings from a Canadian multi-site quality of work life cross-sectional survey. BMC Health Service Research, 2(6), 6. https:// doi.org/10.1186/1472-6963-2-6

Kumar, B., \& Thomas, B. (2016). An empirical study on perceived quality of work life and turnover intention among the employees of private hospitals. International Journal of Latest Trend in Engineering \& Technology, 4, 511-519.

Lee, Y.W., Dai, Y.T., Park, C.G., \& McCreary, L.L. (2013). Predicting quality of work life on nurse's intention to leave. Journal of Nursing Scholarship, 45(2), 160-168. https:// doi.org/10.1111/jnu.12017

Louis, K.S. (2006). Effects of teacher quality of work life in secondary schools on commitment and sense of efficacy. International Journal of Research, Policy \& Practice, 9(1), 1-27. https://doi.org/10.1080/0924345980090101

Mahesh, B.P., \& Nanjundeswaraswamy, T.S. (2020). Quality of work life of employees in corporate sector in India. International Transaction Journal of Engineering, Management, \& Applied Science and Technologies, 11(12), 1-10.

Mahmoudi, O. (2015). To investigate the relationship between quality of work life and employee's organisational commitment in the governmental agencies Iran. Academic Journal of Psychological Studies, 4(4), 206-217.

Marshall, G.H., \& Stephenson, S.M. (2020). Burnout and turnover intention among electronics manufacturing employees in South Africa. South African Journal of Industrial Psychology, 46(0), 1-11. https://doi.org/10.4102/sajip.v46i0.1758

Metin, K., \& Asli, K. (2018). The relationship between organisational commitment and work performance: A case of industrial enterprises. Journal of Economic \& Socia Development, 5(1), 48-59.

Mosadeghrad, A.M. (2013a). Quality of work life and turnover intention: Implications for nursing management. International Journal of Research in Nursing, 4(2), for nursing management. International Journal

Mosadeghrad, A.M. (2013b). Quality of work life: An antecedent to employee turnover intention. International Journal of Health Policy \& Management, 1(1), 43-50. https://doi.org/10.15171/ijhpm.2013.07

Mosadeghrad, A.M., Ferlie, E., \& Rosenberg, D. (2011). A study of relationship between job stress, quality of working life and turnover intention among hospital employees. Health Service Management Research, 24(4), 170-181. https://doi. org/10.1258/hsmr.2011.011009

Moshoeu, A.N., \& Geldenhuys, D.J. (2015). Job insecurity, organisational commitment and work engagement among staff in an open distance learning institution. South African Business Review, 19(1), 22-43. https://doi.org/10.25159/1998-8125/5832

Nanjundeswaraswamy, T.S., Swamy, D.R., \& Nagesh, P. (2019). Leadership styles in mediating the relationship between quality of work life and employee commitment. International Journal of Quality Research, 14(2), 387-412. https:// doi.org/10.24874/IJQR14.02-04

Nenadal, J. (2016). Adequacy, suitability, effectiveness and efficiency of quality management systems: How to perceive and assess them. Quality Innovation Prosperity (QIP), 20(2), 39-52. https://doi.org/10.12776/qip.v20i2.736

Nethmini, L.D.P., \& Ismail, M.B.M. (2019). Descriptive statistics of employee performance in brandix company. International Journal on Global Business Management \& Research, 8(1), 51-57.

Noe, R.A. (2010). Employee training and development (4th edn.). New York, NY: McCraw-Hill/Irwin.

Normala, D. (2010). Investigating the relationship between quality of work life and organisational commitment amongst employees in Malaysian firms. Internationa Journal of Business \& Management, 5(10), 75. https://doi.org/10.5539/ijbm. v5n10p75

Paltu, A., \& Brouwers, M. (2020). Toxic leadership: Effects on job satisfaction, commitment, turnover intention and organisational culture within the South African manufacturing industry. South African Journal of Human Resource Management, 18(0), 1-11. https://doi.org/10.4102/sajhrm.v18i0.1338 
Potgieter, I.L., \& Mokomane, S.E. (2020). Implementation of HRM functions in selected small manufacturing companies in Ga-Rankuwa industrial area, Gauteng, South Africa. South African Journal of Human Resource Management, 18, 1-11. https:// Africa. South African Journal of Hum
doi.org/10.4102/sajhrm.v18i0.1282

Ramayah, T., Lo, E.C., \& Tarmizi, A.N. (2014). Quality of work life and turnover intention: A partial least square (PLS) approach. Social Indicators Research, 119(1), 405-420. https://doi.org/10.1007/s11205-013-0486-5

Risla, M.K.F., \& Ithrees, A.G.I. (2018). The impact of quality of work life on organisational commitment with special reference to department of community-based correction. Global Journal of Management \& Business Research, 18(1), 20-29.

Rostiana, R. (2017). The quality of work life influence to turnover intention with person-organisation fit and organisational commitment as mediators. International Journal of Economics \& Management, 11(1), 45-57

Sahni, J. (2019). Role of quality of work life in determining employee engagement and organisational commitment in telecom industry. International Journal of Quality Research, 13(2), 285-300. https://doi.org/10.24874/IJQR13.02-03

Simons, H., \& Usher, R. (2000). Situated ethics in educational research. New York, NY: Routledge.

Sinha, C. (2012). Factors effecting quality of work life: Empirical evidence from Indian organisations. Australian Journal of Business and Management Research, 1(11), $31-40$.
Shahnawaz, G.S., \& Jafri, H.S. (2009). Psychological capital as predictors of organizational commitment and organizational citizenship behavior. Journal of the Indian Academy of Applied Psychology, 35, 78-84

Swamy, D.R., Nanjundeswaraswamy, T.S., \& Rashmi, S. (2015). Quality of work life: Scale development and validation. International Journal of Caring Science, 8(2), 281.

Tabachnick, B.G., \& Fidell, L.S. (2001). Using multivariate statistics (4th edn.). Boston, MA: Allyn \& Bacon.

Van der Berg, Y., \& Martins, N. (2013). The relationship between organisational trust and quality of work life. South African Journal of Human Resource Management 11(1), 1-13. https://doi.org/10.4102/sajhrm.v11i1.392

Viljoen, A., Kruger, S., \& Saayman, M. (2014). Understanding the role that quality of work life of food and beverage employees plays in perceived service delivery and productivity. Southern African Business Review, 8(1), 27-52. https://doi.org/ $10.25159 / 1998-8125 / 5644$

Wallace, J., Hunt, J., \& Richards, C. (1999). The relationship between organisational culture, organisational climate and managerial values. International Journal of culture, organisational climate and managerial values. International Journal of
Public Sector Management, 12(7), 548-564. https://doi.org/10.1108/0951355 Public Sector

Yusoff, Y.M., Rimi, N.N., \& Meng, C.H. (2015). A study of quality of work life, organisational commitment and turnover intention. Problems \& Perspectives in Management, 13(2), 2515-2519. 